\title{
Chromosomal Polymorphism in Sweet Potato Weevil, Cylas formicarius
}

\author{
Akey C.F. Hung ${ }^{1}$ \\ College of Agriculture and Life Sciences, \\ University of Guam, Mangilao, Guam, U.S.A.
}

Accepted June 2, 1984

The sweet potato weevil, Cylas formicarius (sens. lat.) occurs throughout the tropical and subtropical regions of the world where it infests sweet potato, Ipomoea batatas, both in the field and in storage. It presumably entered the United States from the West Indies, with the first case reported in the vicinity of New Orleans in 1875 (Edmond 1971). This insect has now spread throughout the eastern half of Texas, the southern one-third of Louisiana, the coastal counties of Mississippi, Alabama, and Florida and certain areas in the lower coastal plain in South Carolina. Because of its concealed feeding habit, it is difficult to control this pest with conventional insecticide application. As part of a project to develop genetic control methods against this pest, a cytogenetic study of the sweet potato weevil was carried out at the University of Guam in 1979-1980.

\section{Materials and methods}

The insects used in this study were obtained from laboratory colonies maintained at the Asian Vegetable Research and Development Center (Taiwan) (AVRDC), Louisiana State University (Baton Rouge) (LSU), the University of Hawaii (Honolulu), and from infested sweet potato on Guam and Tinian. These five cultures were maintained individually in one-gallon glass jars with sweet potato at $28^{\circ} \mathrm{C}$. Pupae were collected by manually breaking open the potatoes. Chromosome preparations were made using the technique of Hung et al. (1972). At least 20 well spread cells from either ovaries or testes were studied in each pupa. Chromosome photographs were taken with a Wild M20-EB Phase Microscope using Fuji Minicopy film.

\section{Results and discussion}

Manna and Lahiri (1972) and Sharma et al. (1980) reported $10 \mathrm{AA}+\mathrm{Xy}_{\mathrm{p}}$ as the chromosome number and sex determining mechanism in C. formicarius Fab. from India. According to Smith and Virkki (1978), the same karyotype is found in the Puerto Rican strain, C. f. elegantulus (Summers). This chromosome constitution was also found in most of the materials studied (Fig. 1). However, at

1 Present Address: Beneficial Insect Introduction Laboratory, Beltsville Agricultural Research Center-East, USDA, Beltsville, Maryland 20705, U.S.A. 

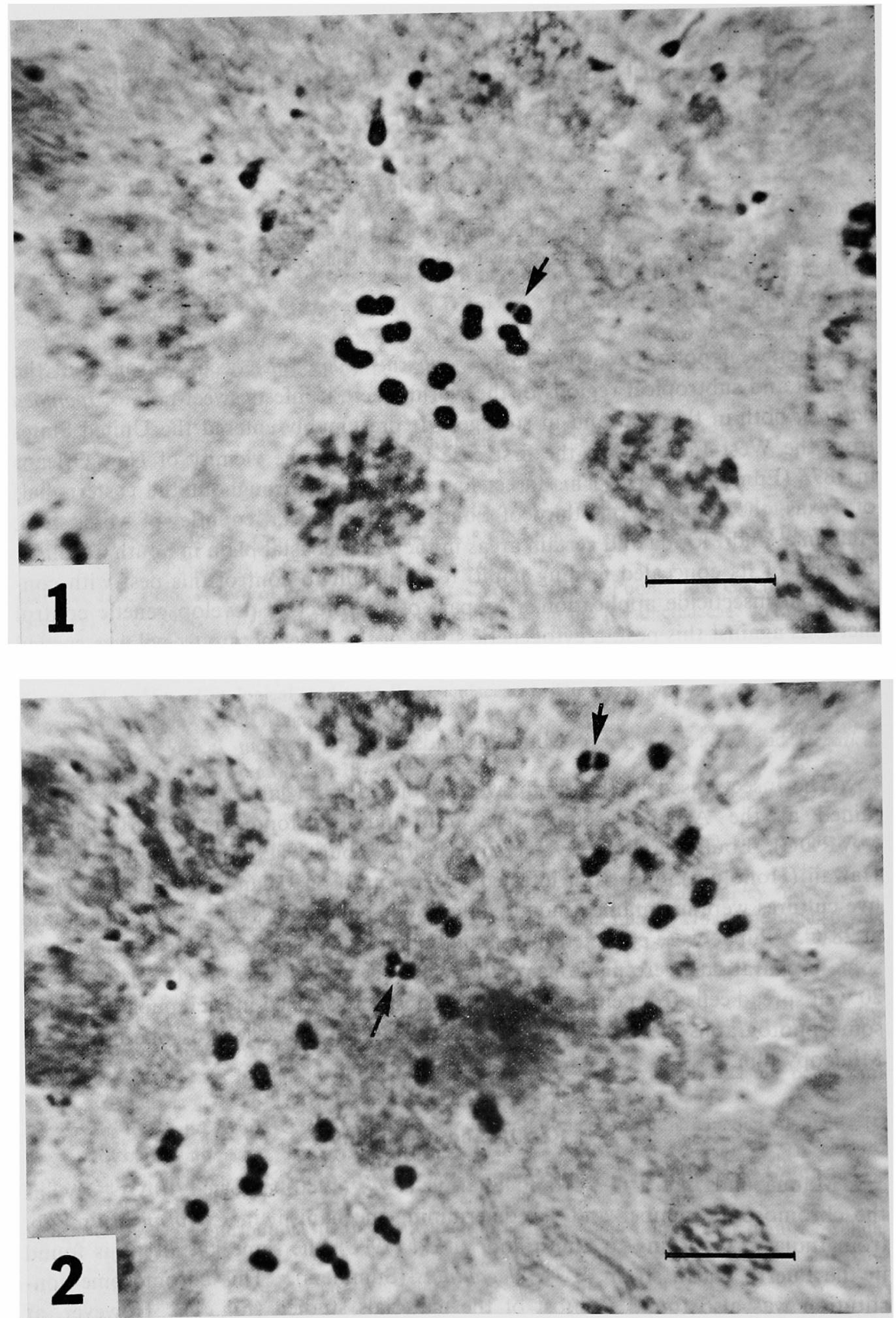

Figs. 1-2. Chromosome consitution in sweet potato weevil. 1, $\mathrm{Xy}_{\mathrm{p}}$ association in male from Hawaii. 2, XY and $\mathrm{Xyy}_{\mathrm{p}}$ association in the testes of one male from Louisiana. (Arrows indicating sex chromosomes). Scale $=10$ microns. 
least 3 sex chromosome systems were found in these materials, i.e., 10AA+XX for females in all cultures with the males showing either $10 \mathrm{AA}+\mathrm{XY}$ or $10 \mathrm{AA}+\mathrm{Xyy}_{\mathrm{p}}$ or $10 \mathrm{AA}+\mathrm{XY}_{\mathrm{p}}$. In some cases, two sex chromosome systems were found in the same male (Fig. 2 and Table 1). Therefore, most males from the LSU culture were $10 \mathrm{AA}+\mathrm{XY}$ and a few individuals exhibited both $\mathrm{XY}$ and $\mathrm{Xyy}_{\mathrm{p}}$ karyotypes. The culture from Hawaii had only $\mathrm{Xy}_{\mathrm{p}}$ males. Those from Guam, Tinian and Taiwan were mostly $\mathrm{Xy}_{\mathrm{p}}$, but some were $\mathrm{Xyy}_{\mathrm{p}}$ and a few had both the $\mathrm{Xyy}_{\mathrm{p}}$ and $\mathrm{X} \mathrm{y}_{\mathrm{p}}$ karyotypes in the same individual.

Table 1. Frequency of sex chromosome constitution in males from 3 localities

\begin{tabular}{lrcccc}
\hline \hline & $X Y$ & $X Y+X y y_{p}$ & $X_{y}$ & $X y y_{p}+X y_{p}$ & $X y_{p}$ \\
\hline LSU & 15 & 3 & 0 & 0 & 0 \\
Hawaii & 0 & 0 & 0 & 0 & 97 \\
AVRDC & 0 & 0 & 1 & 6 & 18 \\
\hline
\end{tabular}

The $\mathrm{Xyy}_{\mathrm{p}}$ sex determining mechanism has also been reported in the following 4 species of curculionids: Scepticus insularis Roelofs (Takenouchi 1969b), Deporaus pacatoides Voss (Takenouchi 1969c), Diocalandra sp. (Takenouchi 1969d), and Depotaus unicolor Roelofs (Takenouchi 1970). Takenouchi also reported chromosomal polymorphism in the weevils Phyllobius longicornis Roelofs (Takenouchi 1969a), Baris ezoana Kono (Takenouchi 1971), Telephae konoi Morimoto (Takenouchi 1972b), and Catapionus gracilicornis Roelofs (Takenouchi 1976). Intraindividual chromosomal variation has been reported in the weevils Sitona sp. (Takenouchi 1972a) and Okikuruminus roelofsi Harold (Takenouchi 1973). However, in most of these cases only the autosomes were involved. The results reported here represent the first case of male sex chromosome polymorphism among populations and within the germ line of the same individual curculionid beetle.

Although taxonomists refer to the Old World sweet potato weevil as C. formicarius and New World populations as $C$. $f$. elegantulus, there are no distinct morphological differences between my samples from Louisiana and those from Asia, even in the male genitalia (Horace R. Burke, personal communication). However, preliminary isozyme studies also show that the Louisiana culture is different from the other cultures in at least two enzyme systems (Hung, unpublished data). This and the fact that the Louisiana culture is the only one with an XY system indicates the possibility of reproductive incompatibility between New World and Old World sweet potato weevils. Unfortunately, cross-breeding information is not available for assessing this biological character.

\section{Summary}

Karyotype and sex-determining system of Cylas formicarius from Louisiana were determined as $10 \mathrm{AA}+\mathrm{XX}$ in females, and $10 \mathrm{AA}+\mathrm{XY}$ in most males with a few individuals exhibited both $X Y$ and $X y y_{p}$ karyotypes. The culture from Hawaii had only $\mathrm{Xy}_{\mathrm{p}}$ males, those from Guam, Tinian and Taiwan were mostly $\mathrm{Xy}_{\mathrm{p}}$, al- 
though some were $\mathrm{Xyy}_{\mathrm{p}}$ and a few had both the $\mathrm{Xyy}_{\mathrm{p}}$ and $\mathrm{Xy} \mathrm{y}_{\mathrm{p}}$ karyotypes in the same individual.

\section{Acknowledgements}

I am grateful to Dean W. P. Leon Guerrero, Associate Dean R. Muniappan, J. L. Demeterio, Marilou T. Baccay, Sandra L. Dela Garza, and Rosalee Kikuchi for helping me to carry out this study in Guam. I thank M. Ali, T. B. Barlow, D. Muruvanda, L. H. Rolston and N. S. Talekar for sending me live cultures, H. R. Burke for identifying the specimens, and C. Goodpasture and Y. Takenouchi for reviewing the manuscript. This study was supported in part by USDA Regional Project W-84.

\section{References cited}

Edmond, J. B. 1971. Sweet Potatoes: Production, Processing, Marketing. The AVI Publ. Co. Inc., Westport, Connecticut. 334 pp.

Hung, A. C. F., Imai, H. T. and Kubota, M. 1972. The chromosomes of nine ant species (Hymenoptera: Formicidae) from Taiwan, Republic of China. Ann. Entomol. Soc. Amer. 65: $1023-1025$.

Manna, G. K. and Lahiri, M. 1972. Chromosome complement and meiosis in forty-six species of Coleoptera. Chrom. Inform. Serv. 13: 9-11.

Sharma, G. P., Gill, T. K. and Pal, V. 1980. Chromosomes in the curculionoid beetles (Coleoptera: Curculionoidea). Coleopt. Bull. 34: 361-367.

Smith, S. G. and Virkki, N. 1978. Animal Cytogenetics, Vol. 3: Insecta 5. Coleoptera. Gebrüder Borntraeger, Berlin-Stuttgart. $366 \mathrm{pp}$.

Takenouchi, Y. 1969a. A study of the chromosomal dimorphism in Phyllobius longicornis Roelofs (Curculionidae: Coleoptera). Japan. J. Genetics 44: 93-96.

- 1969b. The $\mathrm{Xyy}_{\mathrm{p}}$ sex determining mechanism found in Scepticus insularis Roelofs (Curculionidae: Coleoptera). Japan. J. Genetics 44: 189-190.

- 1969c. A chromosome study in a weevil, Depotaus pacatoides Voss (Curculionidae: Coleoptera): an additional instance of the $\mathrm{Xyy}_{\mathrm{p}}$ sex-determining mechanism. Japan. $\mathbf{J}$. Genetics 44: 379-380.

- 1969d. On the compound sex chromosomes in Diocalandra sp. (Curculionidae: Coleoptera). Chrom. Inform. Serv. 10: 4-6.

- 1970. Chromosomal polymorphism in Deporaus unicolor Roelofs (Curculionidae: Coleoptera). Chrom. Inform. Serv. 11: 17-18.

- 1971. Chromosomal polymorphism in a weevil species, Baris ezoana Kono (Coleoptera: Curculionidae). Japan. J. Genetics 46: 355-360.

- 1972a. Intra-individual chromosomal polymorphism in a weevil, Sitona sp. (Coleoptera: Curculionidae). Kontyu 40: 119-121.

- 1972b. A study on the chromosomal dimorphism in Telephae konoi Morimoto (Coleoptera: Curculionidae). Japan. J. Genetics 47: 137-139.

- 1973. Chromosomal polymorphism in Okikuruminus roelofsi Harold (Curculionidae: Coleoptera). Kontyu 41: 330-332.

- 1976. A study on the chromosomal dimorphism is Catapionus gracilicornis Roelofs (Curculionidae: Coleoptera). Japan. J. Genetics 51 : 279-283. 